\section{The Large Non-Conchoidal Fracture-Surfaces of Early Flint Implements.}

WHEN a representative series of flint implements is examined comprising examples of every stage of culture from the Neolithic back to the earliest ChellesPalæolithic specimens, it will be observed that, generally speaking, the older the implements the less they show small and "dilettante" flaking in their manufacture, and that when the earliest Chelles stage is reached the flints have been fashioned by the removal of large, bold flakes not supplemented by secondary work, such as is to be seen upon nearly all the examples of later cultures.

When a further series of implements is examined which predate the earliest Palæolithic specimens, this peculiarity is seen to be still more marked, the flints in many cases having been fashioned solely by "quartering" blows producing clean, flat fracturesurfaces exhibiting neither well-marked cones of percussion nor conchoidal rippling, such as are so often produced by the more ordinary type of blow. If, as often happened in pre-Palæolithic times, an implement was produced by means of such blows, the flakes would not in the first place exhibit the normal characteristics of human blows, and secondly, many of these flakes would, in the process of manufacturing the implement, of necessity be truncated and their resemblance to accepted "human" flakes made still smaller. Some of these truncated flakes, moreover, at first sight have the appearance of being thermal breaks, and it requires a close and intelligent examination of their surfaces with a high-power lens to discern those small indications which demonstrate that the flakes have been removed by blows. In addition to the cone of percussion and conchoidal rippling which are often produced by a blow upon a flint, fissures of varying size are also formed which radiate from the point of impact.

Some of these fissures, which appear to me to represent "tears" made in the flint by the cleaving force of the blow, are very minute, but in nearly every case are capable of discernment with a really good lens. I have found by experiment that the "quartering" blow to which $I$ have referred, though not producing a well-marked cone of percussion, and very frequently no conchoidal rippling, nevertheless gives rise to these small fissures, and that it is generally possible by the evidence they afford to determine the exact "fracturing agent" and the direction in which it has acted.

It seems to me to be necessary for the prehistorian to recognise the real meaning of these peculiar fracture-surfaces of early flint implements, and I think their non-recognition has been the cause of the inability of many observers to accept these, specimens as having been humanly fashioned. To those, however, who are familiar with the method of production of such fracture-surfaces it becomes clear that great precision and dexterity are needed to make an implement by means of this particular type of blow, and that in consequence the probability of unguided natural forces having produced them is practically climinated.

I2 St. Edmund's Road, Ipswich, September I2. No. 2343, vol. 94]

\section{BRITISH AERONAUTICS. ${ }^{1}$}

THE fact that methods of experinent and the apparatus used for test have become standardised has rendered it possible to add considerably to the detailed knowledge relating to aeronautics, and the result is reflected in the increased size of the annual volume published by the Advisory Committee for Aeronautics. The amount of test-work still called for is enormous, and for some time to come problems will need to be taken in order of urgency, whilst many problems of great scientific interest are left for later consideration. Amongst such problems may be classed the mathematical investigation of motion such as that illustrated in Fig. I, which shows a photograph of fluid motion round a model of an aeroplane wing. The photograph had a timeexposure of about one second, and the lines indi- 